\title{
Global Content Protection Through Automation - A Transnational Law Perspective
}

\author{
Henning Grosse Ruse-Khan
}

Published online: 4 October 2018

(C) Max Planck Institute for Innovation and Competition, Munich 2018

When Phillip Jessup coined the term "transnational law" in the 1950s, he tried to capture "all law which regulates actions or events that transcend national frontiers. Both public and private international law are included, as are other rules which do not wholly fit into such standard categories." 1 Within the third category, those "other rules" somewhere in between existing schemas, Jessup specifically included rules emanating from agreements among the parties involved - be it "individuals, corporations, states, organizations of states, or other groups". While he certainly had forms of what we nowadays call "private orders" (like lex mercatoria) in mind, he could not have thought of globally operating online platforms which set their own rules (or "community guidelines"), implement them through their codes and user interfaces, and enforce them through algorithms. Nevertheless, I suggest that it is the notion of transnational law which offers a useful lens to look at developments in the protection of intangible assets which are based on norms set by private actors, often having global reach and a form of direct effect not paralleled by any state enforcement machinery. It enables us to identify as law what we otherwise might discard, and in turn puts a spotlight on the effect and (cross-border) implications of (quasi-)legal orders outside traditional paradigms.

Looking at intellectual property (IP) protection from a transnational law perspective also allows us to see the strategies employed to overcome the central notion of IP rights as territorial, state-granted privileges. While basic forms of

${ }^{1}$ Philip Jessup, Transnational Law (New Haven: Yale University Press, 1956), p. 1.

H. Grosse Ruse-Khan ( $₫)$

Reader in International and European Intellectual Property Law, University of Cambridge, King's

College, Cambridge, UK

e-mail: hmg35@cam.ac.uk 
private ordering (such as cross-border technology licensing) eventually are tied to the state enforcement machinery, ${ }^{2}$ more sophisticated private orders utilize the intangible nature of IP subject matter and find alternative modes of enforcing their rules. This is true in particular for digital content: access to such content (whether copyrighted or not) is subject to clicking on "I agree" to the terms of use (whether or not reflecting exclusive rights and exceptions thereto) imposed by the content provider, compliance with which can be enforced by technological means (in Lessig's terms: code as code). Another well-known example is ICANN's Uniform Dispute Resolution Policy (UDRP) for domain names. Systems of automated content protection online take these strategies a significant step further, not only in terms of complexity and sophistication of the private order they create, but primarily through a significantly more profound, immediate impact of their ordering on others - an impact that supersedes any form of state-sanctioned enforcement. Let me explain further exactly what am I interested in scrutinizing from a transnational law angle.

It is transnational IP norms set by private actors, in the form of content (rather than actual copyright) protection through automated enforcement tools employed by platforms such as YouTube (owned by Google) or Instagram (part of Facebook). I will focus on YouTube's "Content ID" 3 system here, but this is just one (albeit quite sophisticated and complex) example of a broader trend towards parallel legal universes that occasionally reflect state-made IP laws, but often diverge from them in significant ways. Driven by the need to avoid liability for the copyright infringements of their users under national laws (especially the DMCA) ${ }^{4}$ and by the desire to optimize monetization of content uploaded by their users, platforms like YouTube frequently rely on upload filters that identify matches with content claimed by others. More often than blocking such uploads, those who claim rights in (parts of) content uploaded by users choose to monetize this content by running adds against it. In contrast to the typically bilateral relations in IP contracts, we are confronted with a tripartite relation between the platform, content owners and users, where the platform agrees to protect content claimed by those eligible for its protection tools, in ways it determines by its technical design, against material provided by users. Note that: (1) you must have a sufficient amount of content on the platform to be eligible for protection; (2) not everything copyrightable under the sun will fall within the "subject matter" of content the platform is willing to protect; (3) the "exclusive rights" afforded by the platform are re-oriented around common options such as monetizing, tracking or blocking user uploads; and (4) findings of

\footnotetext{
${ }^{2}$ While party autonomy would generally allow the contracting parties to opt for arbitration and resulting awards should be enforceable via the New York Convention, states still have some say in the recognition and enforcement process - in the case of IP rights exemplified through arbitrability hurdles when disputes arise over the validity of the IP rights vesting in the licensed technology.

3 To understand the basics of Content ID, see the short (YouTube) video: https://support.google.com/ youtube/answer/2797370?hl=en-GB. A general description of automated enforcement tools by one of the major providers (Audible Magic) is available at https:/www.audiblemagic.com/compliance-service/ \#how-it-works.

4 Content ID is somewhat tied to, but runs essentially in parallel to the notice and take-down tools under the US Digital Millennium Copyright Act (DMCA). See https://support.google.com/youtube/answer/ 2797454.
} 
"infringements" are based on matches that algorithms detect between (parts of) a user upload and a content reference file. ${ }^{5}$ Most who are vaguely familiar with copyright law will find sometimes more but often, however, less in common with traditional legal concepts of authorship, literary and artistic works, exclusive rights and determinations of infringement.

Another key distinction to other types of private ordering (such as creative commons or technology licensing frameworks) is the automated enforcement which is part and parcel of content protection through the platform. Once the respective algorithm detects a match (including a partial match) between claimed content and a user upload, the content owner's decision to block, monetize or simply track views of that upload is automatically implemented throughout the platform for all jurisdictions where the owner has claimed this content. While platforms generally offer mechanisms for users to dispute a claim by a content owner, this often is no more than a request for the content owner to reconsider its claim over the upload. ${ }^{6}$ Effectively, this may mean that a user has to take legal action to claim that, under the applicable national law, for example: (1) the claimed content is not copyright protected; (2) the amount utilized does not amount to an infringement; or (3) an exception or other defense applies. Since the platform operates with inbuilt and automated content protection, it appears to be on users to take matters into their own hands (and eventually to the courts) to enforce their "rights". The problem, of course, is that by and large, copyright laws do not conceptualize the various limits to copyright protection as "user's rights". Arguably, in the world prior to automated enforcement, there was no need for this since the user would normally ${ }^{7}$ just use content and then copyright owners would need to take action to enforce their rights. Automated content protection through the platform turns this on its head - which requires us to rethink ways to properly conceptualize limits to copyright in this context. In an environment where those who assert ownership over content determine what is protected, and the platform defines how and where these determinations are directly enforced through algorithms, society needs new and effective tools that re-enforce the public domain.

So what follows from a transnational law perspective here? Capturing these trends as law and then looking at their implications is what transnational law can do better than the more traditional approaches to (international) law. A public international law approach would disqualify private rules as relevant law ${ }^{8}-$ and thus

\footnotetext{
5 For Content ID see https://www.youtube.com/content_id_signup, https://support.google.com/youtube/ answer/1311402 and https://support.google.com/youtube/answer/107383.

${ }^{6}$ For Content ID, see https://support.google.com/youtube/answer/2797454 where after an unsuccessful "appeal" to the content owner (which requires the latter to request a copyright takedown, based on the DMCA), the user can submit a counter-notification under the DMCA. It seems that such a counternotification in turn requires the content owner to provide YouTube with evidence that (s)he has initiated court proceedings against the user - see https://support.google.com/youtube/answer/2807684?hl=enGB\&ref_topic=2778545). It, however, remains unclear whether (and especially how) this system will work with regard to content claimed for non-US jurisdictions where the DMCA does not apply.

7 With the exception of situations where technological protection mechanisms (TPMs) are deployed.

${ }^{8}$ Of course, there is a long-standing debate about the (human rights) responsibilities of private actors under international law - but this has not moved much beyond optional guiding principles for these actors.
} 
effectively neglect the global reach of some of these private ordering regimes (whose impact may easily surpass that of minimum standards set in public international law treaties on IP). On the other hand, a traditional private (international) law perspective would zoom in on an individual case of a crossborder use of IP-protected content and identify the forum with jurisdiction to decide as well as the applicable law. In the relations between the platform and those who claim to own content, the basic principles of party autonomy and freedom of contract govern in a way that makes it easy to overlook the third-party effects of their private ordering. These principles, of course, are justified by the idea that private parties can freely agree on their legal relations among themselves - unless there is a public policy reason to intervene (such as the need to protect a weaker party, as in employment and consumer contracts). In the context of content protection by platforms, however, any contractual agreement between content owners and the platform has effects well beyond their legal relations. It covers all users of the platform - whether they actively upload content or simply retrieve content through the platform. It affects them in that it curtails - as shown above their ability to use, retrieve and enjoy content within the framework of what their "lex loci protectionis" IP regime allows.

Unless those users have validly agreed to the content protection enforced through the platform, the notion of party autonomy and freedom of contract offers insufficient grounds for the creation of private content protection regimes with global reach. The argument that users are free not to use the platform neglects the fact that many of these platforms nowadays function as essential facilities in accessing and communicating content online. Their role in facilitating freedom of speech and information has been recognized by courts, which take this function into account when determining platform liability, for example, for direct and indirect copyright infringements. ${ }^{9}$ If platforms hence are privileged based on their public interest function, why should they not also have to be held responsible to actually fulfil this function? While it may be hard to say when and under which circumstances platforms begin to serve a public interest function, and if so what responsibilities this exactly entails, it seems clear from a transnational law perspective that they cannot be judged simply on the basis of the freedoms to design their private law relations.

So what should be done? This brief editorial is primarily meant to offer a fresh mode of analysis on an issue which has been subject to emerging scholarship and thinking - mainly from a domestic IP, competition or human rights perspective. It has pointed to the quasi inter-omnes and essentially global effects of private orders, set by the winners of "digital capitalism". It is perhaps time to address these effects and to look at platforms on that basis. Various (domestic) legal regimes come to mind - from competition law, regulatory approaches akin to those applicable to public utilities, corporate human rights responsibilities, to private contract (especially consumer protection), IP and tort law. Whatever route is taken, the

\footnotetext{
9 See CJEU judgments in Case C-360/10, SABAM v. Netlog (16 February 2012), paras. 48-50; and Case C-314/12, UPC Telekabel Wien v. Constantin Film Verleih (27 March 2014), paras. 55-57; and in particular the decision of German Federal Supreme Court (BGH) in Vorschaubilder III (I ZR 11/16 - 21 September 2017), paras. 60-62.
} 
outcome needs to reinforce a normative foundation which is increasingly under attack: that exclusivity is the exception, and freedom to access and use is the general rule. That freedom is a common good which belongs to all of us. Restricting it requires justifications, and where they are lacking there should be accountability as much as those infringing justified exclusivity are liable. 